\title{
Antiplatelet Drugs and Its Gastrointestinal Side Effects among Ischemic Stroke Patients in Dr. Hasan Sadikin General Hospital 2011
}

\author{
Ananthakrishnan A/L Rajendram ${ }^{1}$, Ike Rostikawati Husen ${ }^{2}$, Andi Basuki ${ }^{3}$ \\ ${ }^{1}$ Faculty of Medicine, Universitas Padjadjaran ${ }^{2}$ Department of Pharmacology and Therapy, \\ Faculty of Medicine, Universitas Padjadjaran, ${ }^{3}$ Department of Neurology, Faculty of Medicine, \\ Universitas Padjadjaran/Dr. Hasan Sadikin General Hospital Bandung
}

\begin{abstract}
Background: Antiplatelet drugs with known side effects are given in long term therapies to prevent secondary ischemic stroke. Gastrointestinal side effect is the most prevalent issue. The aim of this study was to identify which antiplatelet drugs have the most gastrointestinal side effects and the duration of administration.

Methods: Seven hundred twenty six medical records were obtained from the Medical Record Department of Dr.Hasan Sadikin General Hospital Bandung from August to December 2011. Inclusion criteria were $>18$ years old and treated by long term antiplatelet drugs with complete medical records. Data analyzed descriptively consist of antiplatelet type, gastrointestinal effects, and drug administration duration.

Results: Of 726 medical records only 246 were enrolled this study. Aspirin $80 \mathrm{mg}$ was the most frequent drug given to ischemic stroke patients (65.9\%). Gastrointestinal (GI) bleeding and nausea were the two side effects mostly found in aspirin >80 mg group (90\%; 95\% respectively). The side effects was found after less than 3 months in the aspirin $>80 \mathrm{mg}$ group, while it took longer to appear in clopidogrel $75 \mathrm{mg}$ group.

Conclusions: Aspirin ( $>80 \mathrm{mg}$ ) presents the most frequent gastrointestinal side effect compared to low dose aspirin $80 \mathrm{mg}$, clopidogrel, and combination of clopidogrel and aspirin.
\end{abstract}

Keywords: antiplatelet, ischemic stroke, side effects

\section{Introduction}

By definition, a stroke is "rapidly developing clinical signs of focal (or global) disturbance of cerebral function, with symptoms lasting 24 hours or longer or leading to death, with no apparent cause other than of vascular origin". . If blood flow is stopped for longer than a few seconds, the brain cannot get blood and oxygen causing ischemia and the brain cells can die, causing permanent damage to the brain.2 Stroke is the second leading cause of death worldwide and the first in Indonesia. ${ }^{3}$ Worldwide number of deaths resulted by stroke is 150,000 per year. The prevalence of stroke in Indonesia is 500 per 100,000 people. Stroke incidence increases with age especially over 65 years old and the chances of stroke are more common in men than women and tend to run in the families. ${ }^{2,4,5}$

There are two major types of stroke, the ischemic stroke and the hemorrhagic stroke. Ischemic stroke happens when a blood vessel that supplies blood to the brain is blocked by a blood clot. Ischemic strokes may also be caused by clogged arteries which is due to plaque formation by atherosclerosis.1 There is many kinds of combination therapy used in the management of ischemic stroke. Ischemic stroke patients are usually treated with the intravenous thrombolysis, antiplatelet and anticoagulant treatment and the stroke rehabilitation. The intravenous treatment is usually done in case within 3 hours of onset.

The antiplatelets are used to prevent artherothrombotic events by inhibiting the formation of intra-arterial platelet aggregation. Aspirin, clopidogel and the combination aspirin-dipyridamole are widely used to serve this purpose. ${ }^{6}$ Aspirin acetylates platelet cyclooxygenase and irreversibly inhibits the formation of thromboxane A2 functioned to aggregate platelet and cause vasoconstriction. Triclopidine and clopidolgel block the adenosine diphosphate (ADP) receptor on platelets and prevent the activation of the glycoprotein IIb/IIIa receptor which causes

Correspondence: Ananthakrishnan A/L Rajendram, Faculty of Medicine, Universitas Padjadjaran, Jalan Raya BandungSumedang Km.21, Jatinangor, Sumedang, Indonesia, Phone: +628170209396 Email: anan_16v@hotmail.com 
fibrinogen binding to the platelet and platelet aggregation. Dipyridamole is an antiplatelet which inhibits the uptake of adenosine. It can lead to the accumulation of adenosine which causes inhibition of aggregation. ${ }^{7}$

Low dosages of these drugs are given as treatment for the ischemic stroke patients. Whether these drugs are not continued nor the treatment fails, a secondary stroke is most likely inevitable and the patients prognosis is very poor with permanent disability.7,8 The treatment is very important to ensure a good prognosis for the patient, however, all these drugs result in side effects. Most studied has agreed with long term usage of these drugs. These antiplatelet drugs cause gastrointestinal bleeding, nausea, skin rash, diarrhoea and neutropenia. ${ }^{8,9,10}$ In some cases, other drugs are given to counter the side effects of these antiplatelet drugs such as ranitidine and omeprazole.

This has intrigued the researcher to find out about the side effects caused by these antiplatelet drugs of different types in its long term usage by stroke patients especially gastrointestinal effect. By this study, it can be found the evidence of the best regiment of drugs in preventing the gastrointestinal side effects caused by these antiplatelet drugs. This will enhance the management and monitoring plan of the doctor's treatment of ischemic stroke patients to have a better effect.

\section{Methods}

The study was done descriptively by analyzing the secondary data from the medical records of adult ischemic stroke patients aged $>18$ years, being treated with long term antiplatelet drugs in Department of Neurology in Dr. Hasan Sadikin General Hospital, Bandung from January 2011 until December 2012 with complete medical records. Long term of antiplatelet administration is defined as patients taking the drug for a period of $>2$ months. The data will be collected in a systemic random method where the interval is every 2 weeks and collected with the permission fromthe main director of Dr. Hasan Sadikin General Hospital, Bandung and Department of Research and Training of Dr. Hasan Sadikin General Hospital, Bandung. The exclusion criteria were patients with history or present with idiopathic thrombocytopenic purpura (ITP) or other genetic disorder, patients with history or present illness of bone marrow, patients with severe renal or hepatic insufficiency, patients with history of thrombocytopenia or neutropenia, patients with history of any antiplatelet drug sensitivity and any patient with an incomplete medical record.

\section{Results}

Of 726 medical records collected, 246 (33.8\%) fulfilled the inclusion and exclusion criteria. Table 1 showed that aspirin $80 \mathrm{mg}$ was the most frequent drug given to ischemic stroke patient 65.9\%. Gastrointestinal (GI) bleeding and nausea two side effects were mostly found in aspirin $>80 \mathrm{mg}$ group which were $90 \%$; 95\% respectively (Table 2 ). The earliest side effect observed was GI bleeding and nausea among aspirin $>80 \mathrm{mg}$ groups which found less than 3 months and the furthest observed among clopidogrel $75 \mathrm{mg}$ users (table 3).

\section{Discussion}

Aspirin being a cox-1 inhibitor is known as having does have known side effects causing GI bleeding, nausea, rash and diarrhea. These side effects did not change among the ischemic stroke patients as well. Thus, among the 76 cases reported having GI bleeding, 34

Table 1 Distribution of The Type of Antiplatelet Drug

\begin{tabular}{lcc}
\hline \multicolumn{1}{c}{ Types of antiplatelet } & Number of patients & Percentage,\% \\
\hline Aspirin, > 80mg & 40 & 16.3 \\
Aspirin, 80mg & 162 & 65.9 \\
Clopidogrel, 75 mg & 30 & 12.1 \\
Aspirin and clopidogrel , 80 mg \& & 14 & 5.7 \\
$75 \mathrm{mg}$ & & \\
Total & 246 & $100 \%$ \\
\hline
\end{tabular}


Ananthakrishnan A/L Rajendram, Ike Rostikawati Husen, Andi Basuki: Antiplatelet Drugs and Its

Gastrointestinal Side Effects among Ischemic Stroke Patients in Dr. Hasan Sadikin General Hospital 2011

Table 2 Gastrointestinal Side Effects among Antiplatelet Drugs

\begin{tabular}{lcccc}
\hline $\begin{array}{c}\text { Side effect/ Drugs } \\
(\mathbf{n}) \%\end{array}$ & Aspirin, 80mg & Aspirin, >80mg & Clopidogrel & C\&A \\
\hline GI bleeding & $34(21)$ & $36(90)$ & $4(13)$ & $2(14)$ \\
Nausea & $38(23)$ & $38(95)$ & $2(7)$ & $2(14)$ \\
\hline
\end{tabular}

*note: C\&A = clopidogrel $75 \mathrm{mg}$ and aspirin $80 \mathrm{mg}$

*note: GI= gastrointestinal

patients (21\%) were on 80mg aspirin, 36 ( $90 \%)$ patients were on $>80 \mathrm{mg}$ aspirin, $4(13$ $\%)$ patients were on clopidogrel and 2 (14\%) patients wasgiven a combination ofboth aspirin $80 \mathrm{mg}$ and clopidogrel $75 \mathrm{mg}$.. This showed that there is a difference of side effect morbidity in aspirin of $80 \mathrm{mg}$ and clopidogrel. It can be seen that of 70 cases, patients taking aspirin of $80 \mathrm{mg}$ has greater side effect than clopidogrel (only 4 cases) and both of them (only 2 cases). It can be concluded that clopidogrel causes lesser morbidity of GI bleeding than aspirin. ${ }^{11}$

Aspirin is further divided into 2 regiments a dosage that less than $80 \mathrm{mg} \mathrm{(21 \% )} \mathrm{and} \mathrm{more}$ than $80 \mathrm{mg}(90 \%)$. The highest incidence of GI bleeding occurred in the patients taking an aspirin with dosage more than $80 \mathrm{mg}$ (90\%) were. It was suggested that the GI side effect among ischemic patients is being influenced by the dosage of the aspirin used. Even though, $80 \mathrm{mg}$ is considered as a low dose of aspirin, the data still suggests that there are side effects due to its administration to the ischemic stroke patient. Nausea is being reported among the patients using aspirin 80mg (23\%), aspirin more than $80 \mathrm{mg}(95 \%)$, clopidogrel (7\%) and the combination of them (14\%). This data showed that nausea often occurred in the patients taking the aspirin with dosage of more than $80 \mathrm{mg}(95 \%)$ compared to clopidogrel $(7 \%) . I t$ can be concluded that clopidegrol is a better antiplatelet drug than aspirin and the combination of them. ${ }^{11}$

The side effects in patients are influenced by a dosage of drug (Table 3 ). It can be observed that the patients taking aspirin more than $80 \mathrm{mg}$ are earlier to inform the side effects than those taking aspirin $80 \mathrm{mg}$. The patients taking clopidogrel are the last to inform the side effect. Based on Table 3, it can be said that the majority of GI bleeding and nausea side effects arise in patients taking aspirin of $80 \mathrm{mg}$ after 6 months until 9 months while in those takingmore than $80 \mathrm{mg}$ before 3 months. Meanwhile, in clopidogrel and the aspirin and clopidogrel combination groups, the side effects only arise after 9 months. The side effects in patients taking clopidogrel, aspirin and the combination of them arise after 9 months. This data provides

Table 3 Duration Antiplatelet Drugs Consumption

\begin{tabular}{lcccc}
\hline $\begin{array}{c}\text { Duration } \\
\text { (months) }\end{array}$ & $\begin{array}{c}\text { Aspirin 80 mg } \\
\mathrm{n}(\%)\end{array}$ & $\begin{array}{c}\text { Aspirin }>\mathbf{8 0} \mathbf{~ m g} \\
\mathrm{n}(\%)\end{array}$ & $\begin{array}{c}\text { Clopidogrel } \\
\mathrm{n}(\%)\end{array}$ & $\begin{array}{c}\text { C\&A } \\
\mathrm{n}(\%)\end{array}$ \\
\hline GI bleeding & & & & - \\
$<3$ & $4(12)$ & $20(56)$ & - & - \\
$3-6$ & $4(12)$ & $5(14)$ & - & - \\
$6-9$ & $19(56)$ & $8(22)$ & $1(25)$ & $2(100)$ \\
$>9$ & $7(20)$ & $3(8)$ & $3(75$ & - \\
Nausea & $4(12.5)$ & $23(61)$ & - & - \\
$<3$ & $4(12)$ & $3(18)$ & - & - \\
$3-6$ & $19(56)$ & $5(13)$ & - & $2(100)$ \\
$6-9$ & $7(20)$ & $3(8 \%)$ & $2(100)$ & \\
$>9$ & & & & \\
\hline
\end{tabular}


the information that the patients taking aspirin more than $80 \mathrm{mg}$, (56\%) should be monitored carefully in the first 3 months of the drug usage ,those taking aspirin $80 \mathrm{mg}$ (56\%) should be monitored carefully after 3 months to 6 months and those taking the combination of them (75\% and $100 \%$ ) only needs careful monitoring after 9 months.

Most of the patients are still given aspirin eventhough they know about the side effects of it. It is caused by patient's economical status and the drug price. The price of aspirin tablet is ranged from $\mathrm{Rp} 400$ - Rp1,200 while a clopidogrel is ranged fromRp22,000Rp24,000 per tablet.14 The price of aspirin is more economical and affordable for the patients. Yet, clopidogrel showed that it has the lowest side effects of others. It is hoped that it can be a consideration for the doctors when determining about the drug for the patents. ${ }_{11,12}$ The clopidogrel is the best regimen drug that has the least GIl bleeding side effects. Limitation of this study is the aspect of side effects observed only on gastrointestinal effect Further study must carried out to widen other side effects of antitrombotic drug on ischemic stroke. Since the GI effect of antitrombotic drug arise mostly before 3 months, administration of drugs that encounter GI bleeding like ranitidine and omeprazole must be considered before giving high-dosage aspirin. It can be concluded that high dose aspirin ( $>80 \mathrm{mg}$ ) had the most frequent GI side effect compared to low dose aspirin $80 \mathrm{mg}$, clopidogrel, and combination of clopidogrel and aspirin.

\section{References}

1. Thorvaldsen P, Kuulasmaa K, Rajakangas AM, Rastenyte D, Sarti C, Wilhelmsen L. Stroke trends in the WHO MONICA project. Stroke. 1997;28(3):500-6.

2. Fauci A, Braunwald E, Weiner C, Kasper D, Hauser S, Longo D, et al. Harrison's principal of internal medicine: selfassessment and board review. 17th Ed. New York: McGraw-Hill Medical;2008.

3. Misbach J, Ali W. Stroke in Indonesia: a first large prospective hospital-based study of acute stroke in 28 hospitals in Indonesia. J Clin Neurosci.2001;8(3):245-9.

4. Lloyd-Jones D, Adams R, Carnethon M, De Simone G, Ferguson TB, Flegal K, et al. Heart disease and stroke statistics--2009 update: a report from the American Heart Association Statistics Committee and Stroke Statistics Subcommittee. Circulation. 2009;119(3):e21-181.

5. Ingall $\mathrm{T}$. Stroke--incidence, mortality, morbidity and risk. J Insur Med.2004;36(2):143-52.

6. Adams HP, Jr., del Zoppo G, Alberts MJ, Bhatt DL, Brass L, Furlan A, et al. Guidelines for the early management of adults with ischemic stroke: a guideline from the American Heart Association/American Stroke Association Stroke Council, Clinical Cardiology Council, Cardiovascular Radiology and Intervention Council, and the Atherosclerotic Peripheral Vascular Disease and Quality of Care Outcomes in Research Interdisciplinary Working Groups: The American Academy of Neurology affirms the value of this guideline as an educational tool for neurologists. Circulation.2007;115(20) :e478-534.

7. Katzung B, Masters S, Trevor A. Basic and clinical pharmacology. 11th Ed. New York:McGraw-Hill Medical; 2009.

8. Patrono C, Coller B, FitzGerald GA, Hirsh J, Roth G. Platelet-active drugs: the relationships among dose, effectiveness, and side effects: the Seventh ACCP Conference on Antithrombotic and Thrombolytic Therapy. Chest.2004;126(3 Suppl):234S-64S.

9. Prichard PJ, Kitchingman GK, Walt RP, Daneshmend TK, Hawkey CJ. Human gastric mucosal bleeding induced by low dose aspirin, but not warfarin. BMJ.1989;298(6672):493-6.

10. Derry S, Loke YK. Risk of gastrointestinal haemorrhage with long term use of aspirin: meta-analysis. BMJ.2000;321:1183-7

11. CAPRIE Steering Committee. A randomised, blinded, trial of clopidogrel versus aspirin in patients at risk of ischaemic events (CAPRIE).. Lancet.1996;348(9038):1329-39.

12. Rostom A, Moayyedi P, Hunt R. Canadian consensus guidelines on long-term nonsteroidal anti-inflammatory drug therapy and the need for gastroprotection: benefits versus risks. Aliment Pharmacol Ther. 2009;29(5):481-96.

13. Ray WA, Murray KT, Griffin MR, Chung CP, Smalley WE, Hall K, et al. Outcomes with concurrent use of clopidogrel and protonpump inhibitors: a cohort study. Ann Intern Med. 2010;152(6):337-45.

14. Santoso A, Pusponegoro AD, Sani A, Rani HAA, Kartasasmita R, Harimurti GM, 
Ananthakrishnan A/L Rajendram, Ike Rostikawati Husen, Andi Basuki: Antiplatelet Drugs and Its Gastrointestinal Side Effects among Ischemic Stroke Patients in Dr. Hasan Sadikin General Hospital 2011

editors. MIMS edisi Bahasa Indonesia.

2009.

10th ed, Jakarta ;CMP Medica Asia Pte Ltd; 